\title{
Analyzing the Diverse Impacts of Conventional Distributed Energy Resources on Distribution System
}

\author{
Muhammad Aamir Aman ${ }^{1}$, Sanaullah Ahmad ${ }^{1}$, Azzam ul Asar $^{2}$, Babar Noor $^{1}$ \\ ${ }^{1}$ Electrical Engineering Department, IQRA National University, Peshawar, Pakistan \\ ${ }^{2}$ Electrical Engineering Department, CECOS University, Peshawar, Pakistan
}

\begin{abstract}
In recent years, the rapid boost in energy demand around the globe has put power system in stress. To fulfill the energy demands and confine technical losses, researchers are eager to investigate the diverse impacts of Distributed Generation (DG) on the parameters of distribution network. DG is becoming even more attractive to power producing companies, utilities and consumers due to production of energy near to load centers. Reduction in power losses, better voltage profile and less environmental impact are the benefits of DG. Besides renewable energy resources, conventional energy resources are also a viable option for DG. This research aims to analyze the impact of localized synchronous and induction generators on distributions network. The main objectives are to find optimal type, size and location of DG in distribution network to have better impact on voltage profile and reduction in power losses. Using worldwide recognized software tool ETAP and Kohat road electricity distribution network as a test case. Results depicted that at certain buses, positive impacts on voltage profile were recorded while almost $20 \%$ of power losses were decreased when synchronous generator as DG unit was injected in distribution network. Injecting induction generator as DG unit, the results showed increase in power losses due to absorption of reactive power, while improving voltage profile by injecting active power.
\end{abstract}

Keywords-Electric power system; distributed generation; voltage profile; power losses; synchronous generator; induction generator

\section{INTRODUCTION}

In electrical power plants the power is generated which fulfill the demand of energy required. The capacity of generation depends on type and size of the generating unit. Capacities of these traditional power plants vary from hundreds of Megawatt to few Gegawatt [1]. These generation power plants of such a large scale are placed far away from load centers. For transmission of power from the generation station to the customer's premises transmission lines and distribution feeders are used [2], [3]. As shown in Fig. 1, it is necessary for the utilities to provide standard voltage profile/level to its customers.

To balance demand and supply gap, DG became the feasible option. The term DG can be defined as any power generation unit that is integrated within the distributed system [4]. DG may be a conventional or non conventional energy source which consists of wide range of technologies such as internal combustion engines which are prime movers for synchronous and induction generators, wind turbines, photo voltaic systems, fuel-cells, etc. For generation of power if DG

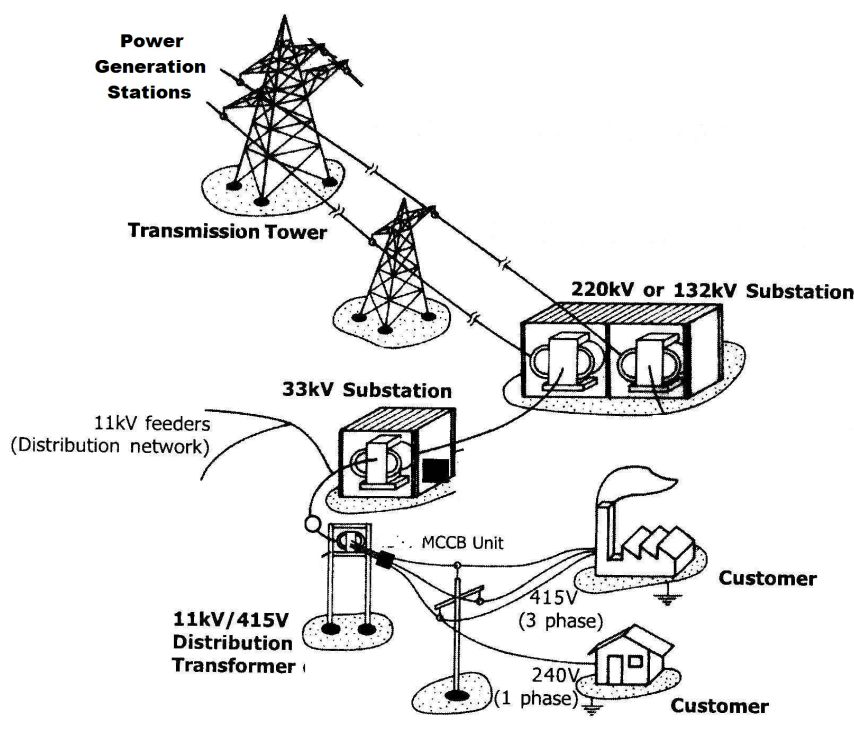

Fig. 1. Traditional power system.

uses non-conventional or renewable energy sources then it is known as renewable distributed generation as shown in Fig. 2 [4].

DG typically ranges from few Kilowatts $(\mathrm{KW})$ to several Megawatts (MW) as they are not centralized [1]. Both conventional (non-renewable) and non-conventional (renewable) resources can be used to generate power for DG [3]. Combustion engines and fuel cell are used as conventional energy resources, while geothermal system, solar energy and wind energy are used as non-conventional energy resources [5]. DG sources accompanied with energy storage technologies is called distributed source of energy as shown in Fig. 2.

As DG is on site generation of power feeding to the distribution network, to acquire a complete and reliable DG system it is more important to have the knowledge of injecting DG at proper optimal location and to determine the source of DG either renewable or non-renewable and also number of DG units. Connection and process of power generation elements linked straightly to distribution system or associated to the network on consumer's location of the meter defines the location of distributed generation [6], [7]. 


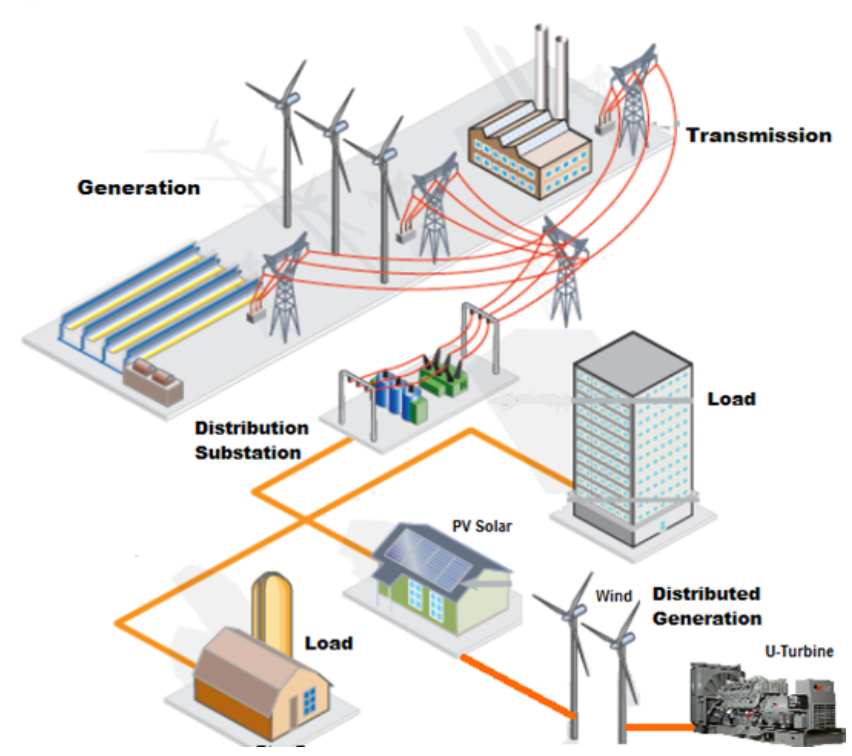

Fig. 2. Localized power distributed generation.

DG is the power generation from the resources which is not centralized and is injected in the distribution system near the load centers. While the traditional power system is linked to the main grid, contains the generation station, transmission network and distribution system. In distribution system voltage and reactive power control equipment, in a current grid system are mostly operated on unidirectional power flow only, that is from the transmission system to high voltage and medium voltage substations and then to the low voltage distribution system. Thus there is decrease in voltage along the feeder, from the substation to the feeder-end. By installing DG makes this statement no longer valid. When DG is injected it will affect voltage profile. Also, when the output power of DG is high then the power may flow from the distribution system to the transmission system which may start false trigging of protection system [8].

DG unit to be effectively is desirable to operate at full capacity. But if they are injected improperly causes restriction and limits its maximum capacity. So, to have undesirable effects on the power system DG unit must be placed at optimal location to operate to its maximum limit [9]. Researchers are eager to develop methods and algorithms to achieve adequate voltage profile and reduce power losses by optimization of DG.

To manage the increasing demand of power and to reduce line losses and voltage profile, DG is considered to be a power paradigm for the new millennium. This depends on optimal location of DG injection and also type of DG to be injected in the power system. If DG is injected in a power system in un-deterministic way a vital impact of DG occurs, causing variation in voltage profile and power losses. Utility companies are searching for a technique to provide standard voltage to the customer's premises. Injection of DG at optimum location is one solution to overcome this problem.

In this paper Electrical Transient Analyzer Program
(ETAP) software tool is used for simulation and analysis. This paper focuses on the impact of DG on voltage profile and power losses in a radial test system in which three cases are considered: firstly results are evaluated when no DG unit is injected, secondly and foremost impact of synchronous generator and induction generator as a DG units are evaluated and lastly comparison for optimum type and location of DG is carried out.

\section{Distributed GENERATION AND ITS DiVERSE IMPACT ON DISTRIBUTION SYSTEM}

Universally DG is accepted as an effective and economical solution to reduce the increasing demand in power system. In current years, DG achieved much consideration due to its positive impacts on the electrical distribution systems. Some of these are improving transmission and distribution congestion, voltage and power quality, line losses reduction, reliability, power consumption demand, security, and reaching the goal to utilize green and renewable energy resources [10], [11]. Also DG has lesser principal cost because of utilizing renewable energy resources and has nil pollutant radiations. DG can work in the situation of peak shaving during increase in requirement and also as a backup in case of interruption.

However, some negative impacts of DG including voltage rise, poor power quality, harmonics, etc. Absence of synchronization between DGs and distribution system results in voltage regulation problems [12].

\section{A. Impact of DG on Voltage Profile and Power Losses}

For positive impacts, DG must be appropriately synchronized with the operational system and feeder scheme. This means addressing concerns allied to voltage regulation, flicker, grounding compatibility, overcurrent safety, harmonic variations, consistency, islanding, capability limits and further aspects. Integration of DG and its impact on system is relative to feeder demand and capacity therefore the coordination of DG with system must be optimized accurately to avoid these issues [13].

It is of prodigious significance to clients having a better voltage profile because its an elementary request for electrical equipment running near the valued voltage. Voltage drop may occur across the distribution transformer due to line impedance, line losses, etc. Thus, rated voltage at customer service would change.

DG supports the voltage to rise at the termination of the feeder. Though, where the DG is introduced may raise the voltage above the standard limits. Voltage may be greater at the consumer amenities than on the primary side of the distribution transformer and may even go beyond the voltage above the higher limits. It means that both high and low service voltage can take place due to the mismatch of DG with the radial power stream.

\section{Power Flow Analysis and Mathematical MODELING}

The electrical network is signified by non-linear algebraic equations under steady state. Power flow solution uses these 
equations. For determining the simultaneous equations iterative methods are used. Different methods are used for solving Gauss-Seidel approach is discussed below.

\section{A. Power Flow Solution by Gauss-Seidel Method}

Gauss-Seidel is one of the iterative methods used for solving non-linear algebraic equations. Complex voltage at every node successively sweeps and updates its neighbor bus voltage in this arrangement.

$$
\mathrm{I}_{\text {Bus }}=\mathrm{Y}_{\text {Bus }} \mathrm{xV}_{\text {Bus }}
$$

And for any particular Bus "a"

$$
\mathrm{I}_{a}=\sum_{n=1}^{N} \mathrm{Y}_{a n} \mathrm{~V}_{n}
$$

The complex power

$$
\begin{aligned}
& \mathrm{S}_{a}=\mathrm{V}_{a} \mathrm{I}_{a}{ }^{*} \\
& \mathrm{P}_{a}+\mathrm{jQ} \mathrm{Q}_{a}=\mathrm{V}_{a}\left[\sum_{n=1}^{N} \mathrm{Y}_{a n} \mathrm{~V}_{n}\right]^{*}
\end{aligned}
$$

Where $\mathrm{a}=1,2,3 \ldots \mathrm{N}$

For complex power

$$
\begin{aligned}
& \mathrm{I}_{a}=\frac{P_{a}+j Q_{a}}{V_{a}^{*}} \\
& \text { Also, } \mathrm{I}_{a}=\sum_{n=1}^{N} \mathrm{Y}_{a n} \mathrm{~V}_{n} \\
& \text { Or, } \\
& I_{a}=Y_{a 1} V_{1}+Y_{a 2} V_{2}+\cdots \cdots+Y_{a a} V_{a}+\cdots \cdots+Y_{a N} V_{N}
\end{aligned}
$$

From the above equation

$$
\mathrm{V}_{a}=\frac{1}{Y_{a a}\left[I_{a}-\left(\sum_{n=1}^{a-1} Y_{a n} V_{n}+\sum_{a+1}^{N} Y_{a n} V_{n}\right)\right]}
$$

or,

$$
\mathrm{V}_{a}=\frac{1}{Y_{a a}\left[\frac{P_{a}+j Q_{a}}{V_{a}^{*}}-\left(\sum_{n=1}^{a-1} Y_{a n} V_{n}+\sum_{a+1}^{N} Y_{a n} V_{n}\right)\right]}
$$

Where, $\mathrm{a}=1,2,3 \ldots \mathrm{N}$

However, suitable determination is desired at per iteration, with proliferation in number of iterations the tolerance reduces because the convergence of this technique is linear. This postures important restriction for large system because of the solution time and estimation cost increases.

\section{B. Gauss-Seidel Iterative Procedure}

1) Make an initial guess $\left|V_{i}\right|=1.0$ and $\delta_{i(0)}=0.00$.

2) Use this solution in power flow equation to obtain the better first solution and this solution is called improved estimated of $\mathrm{V}_{a}$.

3) First solution is used to obtain a better second solution and so on, in general equation i.e.

$$
\mathrm{V}_{a}^{i+1}=\frac{1}{Y_{a a}\left[\frac{P_{a}+j Q_{a}}{V_{a}^{i *}}-\left(\sum_{n=1}^{a-1} Y_{a n} V_{n}^{i+1}+\sum_{a+1}^{N} Y_{a n} V_{n}^{i}\right)\right]} .
$$

\section{RESEARCH Methodology}

For this research work a residential radial distribution feeder of $11 \mathrm{KV}$ located at Kohat Road Peshawar, Khyber Pakhtunkhwa, Pakistan is selected. The selected feeder is modeled and analyzed in Electrical Transient Analyzer Program (ETAP). ETAP software tool is used worldwide for power system planning, designing, operation and analysis.

\section{Modeling of Distributed Generation Units}

For this research work synchronous and induction generator are selected as a DG units. They will operate in different conditions.

\section{A. Without Distributed Generation Unit}

The analysis of the modeled feeder in ETAP will be done when no DG is injected. The results obtained from this case are taken as a reference. The results evaluated from other cases will be compared in order to analyze the impact of different type, size and location of DG on voltage profile and power losses.

\section{B. Synchronous Generator as Distributed Generation Unit}

Synchronous generator as DG unit of $2.5 \mathrm{MW}$ will be modeled and will be placed at different buses in radial distribution system as shown in Fig. 3. The DG unit will inject only real power into the system with unity power factor. Two different places bus- 3 and bus- 6 are selected for connecting DG units randomly.

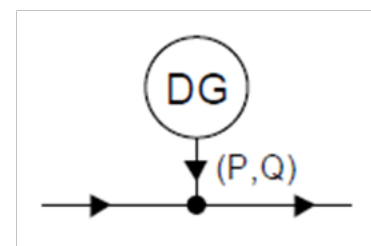

Fig. 3. Synchronous generator as DG.

\section{Induction Generator as Distributed Generation Unit}

An optimum size of 2.5 MW DG will be modeled and injected in the radial distribution system at bus- 3 and bus- 6 randomly as shown in Fig. 4. DG will inject active power and will absorb reactive power, working as an induction generator mode with an operating power factor of 0.85 lagging. 


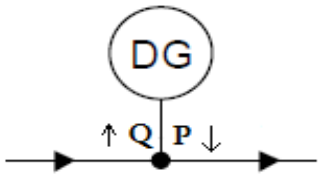

Fig. 4. Induction generator as DG.

\section{Test CASES}

In this research work the following different cases have been conducted:

\section{A. Case-I}

Load flow analysis of the radial distribution network in case-I is shown in Fig. 5. The requirement of load is fulfilled by the power grid as in this case no DG unit is injected. This case is taken as a reference for other cases. Real time condition and voltage levels at different buses are shown. As the red color shows critical condition of buses, bus- 5 and bus- 6 are in critical condition in this case.

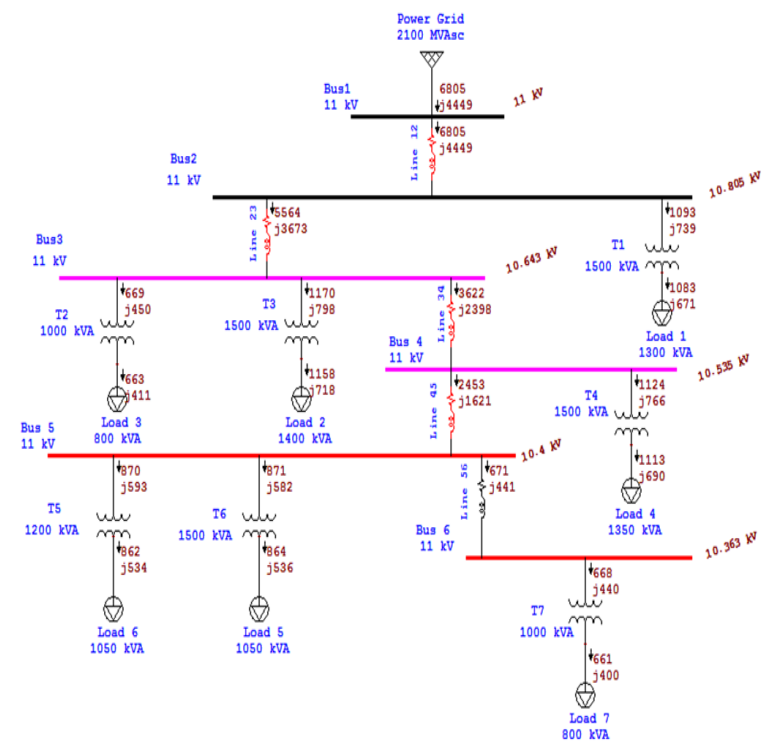

Fig. 5. Without DG unit.

Power losses at distribution transformers and different lines of distribution network are shown in Table I. In this case the total active power losses are $399.7 \mathrm{KW}$ and reactive power losses are 489.9 KVAR.

\section{B. Case-II}

Load flow analysis of Case-II while injecting DG at bus3 are shown in Fig. 6. DG unit of $2.5 \mathrm{MW}$ connected with the system at Bus-3 operating at power factor of unity. Requirement of load is fulfilled by the power grid and DG source mutually in this case. By comparing voltages with previous case voltage level is improved at different buses as shown in Fig. 6.

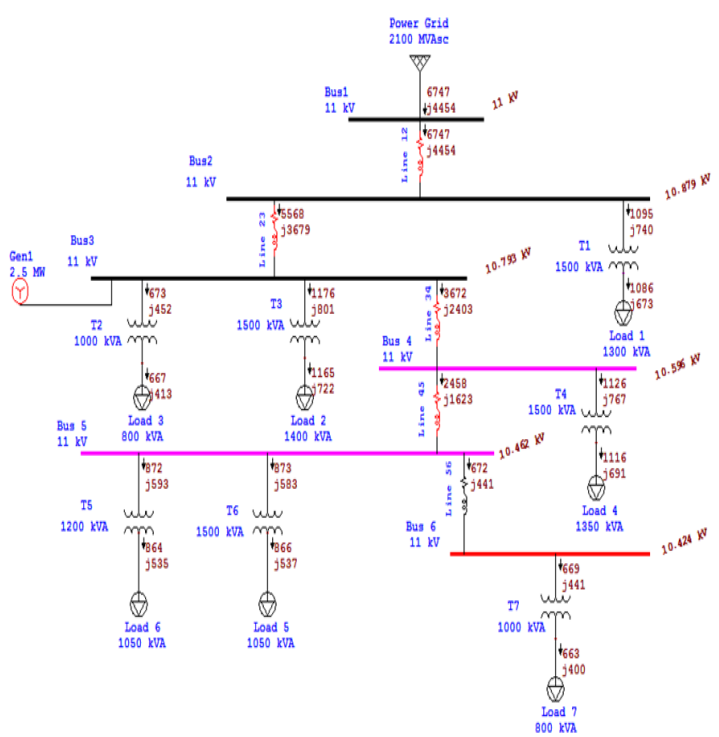

Fig. 6. DG unit connected at bus-3.

The power losses at different locations in distribution network are shown in Table II. These losses are decreased from the previous case when no DG was connected as the total active power losses are $321.3 \mathrm{KW}$ while the total reactive power losses are 481.8 KVAR.

\section{Case-III}

The load flow analysis of Case-III are shown in Fig. 7. A DG unit of $2.5 \mathrm{MW}$ is connected at Bus-6 operating at power factor of 0.85 lagging. Requirements of load is fulfilled by the power grid and DG source mutually. While real power is injected in the system and reactive power is absorbed from the system by the DG unit as connected DG unit is induction generator.

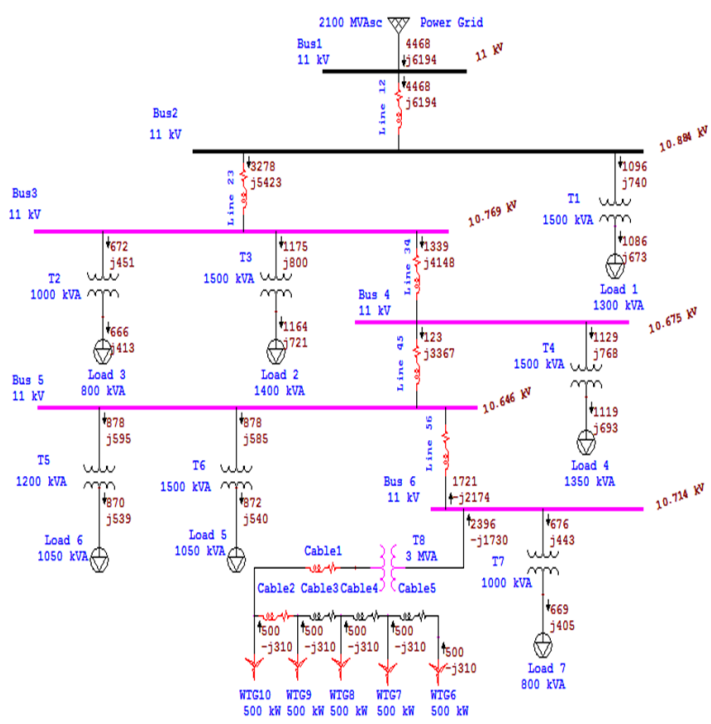

Fig. 7. DG unit of $2.5 \mathrm{MW}$ connected at bus-6. 
TABle I. CASE-I Total Power Losses of the System

\begin{tabular}{|c|c|c|c|c|c|c|c|c|c|c|c|c|c|c|}
\hline \multicolumn{2}{|c|}{ Branch/ Circuit ID } & Line 12 & Line 23 & $\mathrm{~T} 1$ & Line 34 & T2 & T3 & Line 45 & T4 & Line 56 & T5 & T6 & T7 & Total \\
\hline \multirow{2}{*}{ Losses } & KW & 147.8 & 103.0 & 99.7 & 45.1 & 6.3 & 11.4 & 41.2 & 10.8 & 3.1 & 8.3 & 6.5 & 6.5 & 399.7 \\
\hline & KVAR & 37.4 & 26.1 & 67.8 & 11.4 & 39.1 & 80.6 & 6.1 & 75.9 & 0.5 & 58.3 & 46.2 & 40.6 & 489.9 \\
\hline
\end{tabular}

TABLE II. CASE-II Power Losses due InJeCtion of DG UNIT AT Bus-3

\begin{tabular}{|c|c|c|c|c|c|c|c|c|c|c|c|c|c|c|}
\hline Branch/ & ircuit ID & Line 12 & Line 23 & T1 & Line 34 & $\mathrm{~T} 2$ & T3 & Line 45 & $\mathrm{~T} 4$ & Line 56 & T5 & T6 & $\mathrm{T} 7$ & Total \\
\hline \multirow{2}{*}{ Losses } & KW & 83.6 & 47.5 & 9.6 & 87.4 & 6.2 & 11.2 & 40.9 & 10.7 & 3.1 & 8.2 & 6.5 & 6.4 & 321.3 \\
\hline & KVAR & 35.1 & 23.5 & 67.2 & 12.9 & 38.4 & 79.1 & 6.0 & 75.3 & 0.5 & 57.8 & 45.8 & 40.2 & 481.8 \\
\hline
\end{tabular}

The power losses at different locations in distribution network are shown in Table III. When an induction generator unit is connected at bus- 6 the total power losses i.e. active power losses and the total reactive power losses are 522.8 KW and 660.9 KVAR, respectively, as comparing to DG unit placement at Busbar-3 these losses are increased as shown in Table III.

\section{RESULTS AND DisCUSSIONS}

This section discusses the results calculated after the implementation of above cases. Table IV shows a detail report about the real and reactive power injected by DG unit and by grid in each case. The DG unit acts as a negative load when injected in the system.

\section{A. Voltage Profile Analysis}

Different impacts on voltage profile occurs when different types of DG unit are connected with the radial distribution system. Table V shows the overall results.

1) Case-I: In this case no DG unit is injected with the system. Fig. 8 shows the radial decrease in voltage profile from source to load. This reduction in voltage level is due to the line impedance.

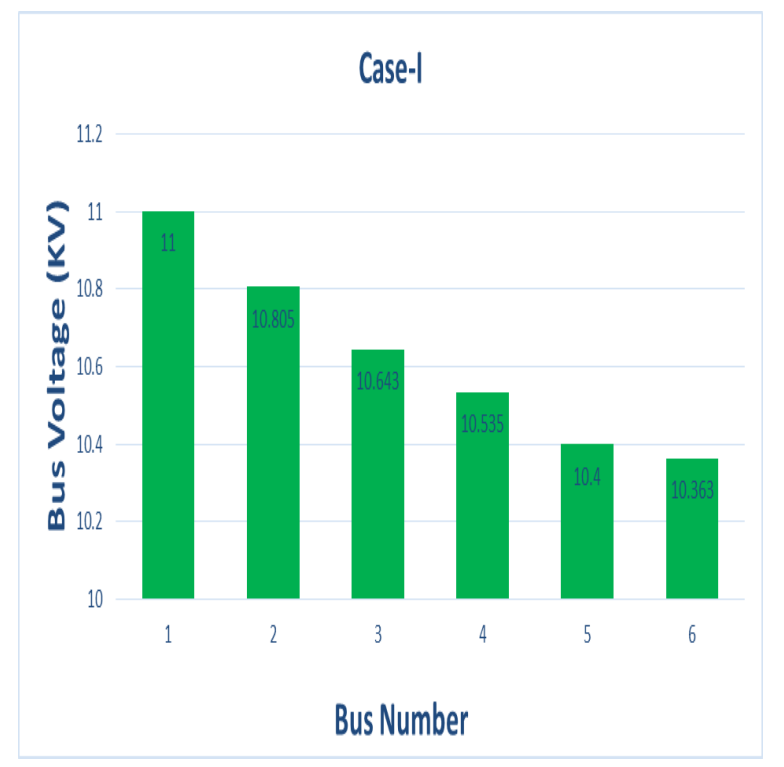

Fig. 8. Radial feeder voltage arrangement.
2) Case-II: $2.5 \mathrm{MW}$ DG unit is installed in this case at Bus3. Operating power factor of this DG unit is unity. Injection of DG unit is considerable effects on voltage profile. Voltage profile is improved in this case. This case shows the best results as comparing it to the other cases. As depicted in Fig. 9.

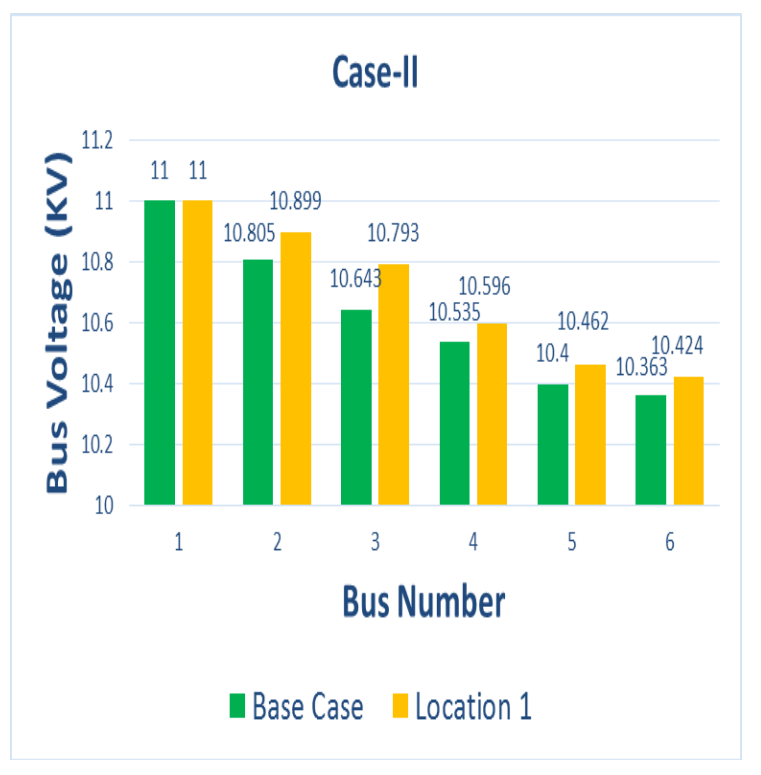

Fig. 9. Impact on voltage profile when active power is injected.

3) Case-III: In this case $2.5 \mathrm{MW}$ capacity of DG unit is injected to the system delivering active power while absorbing reactive power. The result obtained from injection of DG unit at Busbar-6 is shown in the Fig. 10.

The results obtained from injecting synchronous generator at bus-3 are far better than injecting induction generator at bus-6.

\section{B. Power Loss Analysis}

1) Case-I: No DG unit is injected with the radial distribution network in this case. The total power losses of the system are shown in Fig. 11. These losses occur due to line impedances. These losses also consist of some fixed losses which are constant and cannot be changed e.g. transformer losses. There is no DG unit installed in this case and the total power is fed from the power grid. Current flow from the power grid to the consumer localities through each cable results in huge amount of power losses. 
TABLE III. CASE-III Power Losses due to InJection of DG UNit at Bus-6

\begin{tabular}{|c|c|c|c|c|c|}
\hline \multicolumn{2}{|c|}{ Branch/ Circuit ID } & Lines Total & Transformers Total & Cables Total & Total \\
\hline \hline \multirow{2}{*}{ Losses } & KW & 360 & 73.9 & 88 & 522.8 \\
\cline { 2 - 6 } & KVAR & 80.3 & 567.5 & 12.9 & 660.9 \\
\hline
\end{tabular}

TABLE IV. INJECTION OF REAL AND REACTIVE POWER FROM DG UNITS AND GRID

\begin{tabular}{|c|c|c|c|c|}
\hline \multirow{2}{*}{ Case } & \multicolumn{2}{|c|}{ DG Injected Power } & \multicolumn{2}{c|}{ Grid Injected Power } \\
\cline { 2 - 5 } & MW & MVAR & MW & MVAR \\
\hline 1 & 0 & 0 & 6.805 & 4.449 \\
\hline 2 & 2.5 & 0 & 6.747 & 4.454 \\
\hline 3 & 2.5 & -1.55 & 4.468 & 6.194 \\
\hline
\end{tabular}

TABLE V. Different Buses Voltage LeVels

\begin{tabular}{|c|c|c|c|}
\hline No. of Bus & Case-I & Case -II & Case -III \\
\hline \hline 1 & 11 & 11 & 11 \\
\hline 2 & 10.805 & 10.899 & 10.884 \\
\hline 3 & 10.643 & 10.793 & 10.769 \\
\hline 4 & 10.535 & 10.596 & 10.675 \\
\hline 5 & 10.4 & 10.462 & 10.646 \\
\hline 6 & 10.363 & 10.424 & 10.714 \\
\hline
\end{tabular}

2) Case-II: 2.5 MW DG unit injecting active power and power grid mutually fed the load and hence reduces the power losses as shown in Fig. 12. It is clearly seen that losses are reduced by the installation of DG unit.

3) Case-III: $2.5 \mathrm{MW}$ induction generator is injected as a DG unit in this case. This DG setup is delivering active power while absorbing reactive power from the system. The losses in this case are increased from the base case as shown in Fig. 13. The logic behind this increase in losses is that the induction generator absorbs reactive power from the system. It is noted that by injecting synchronous generator at busbar-3 shows the outperform results than by injecting induction generator as a DG in busbar-6. Therefore, injecting DG unit at optimum location i.e. busbar-3 and DG type i.e. synchronous generator will give greater reduction in power losses.

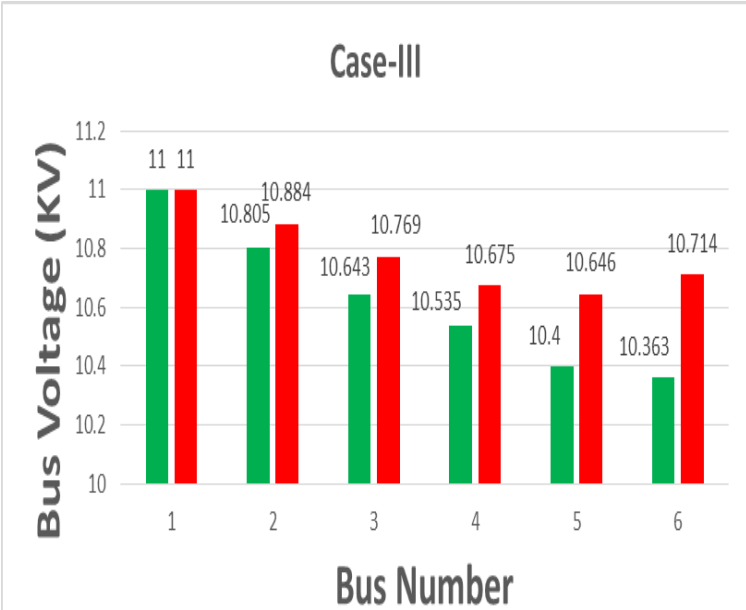

- Base Case Location 2

Fig. 10. Induction generator impacts on voltage profile.

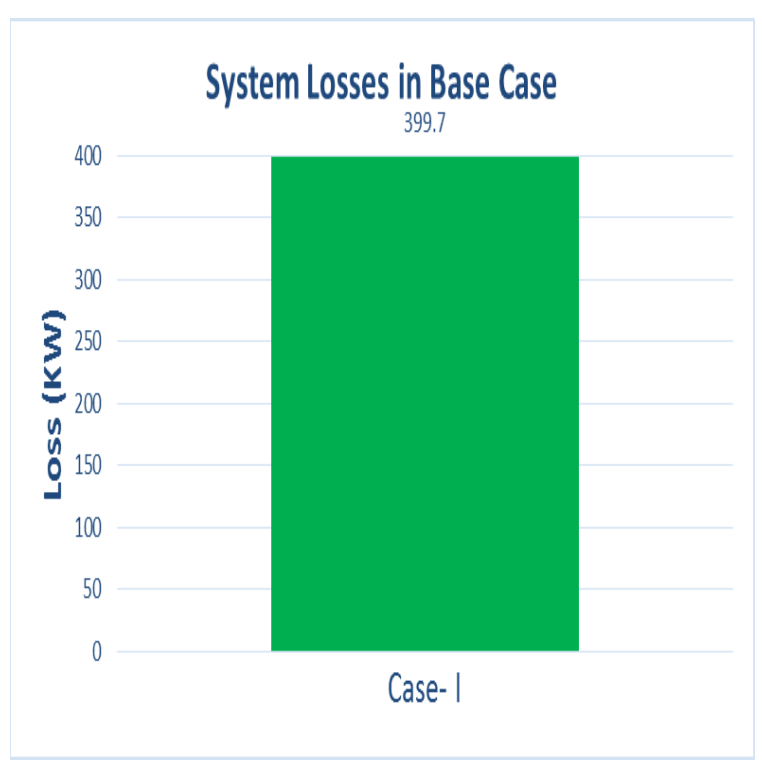

Fig. 11. Total active power losses of the radial distribution system.

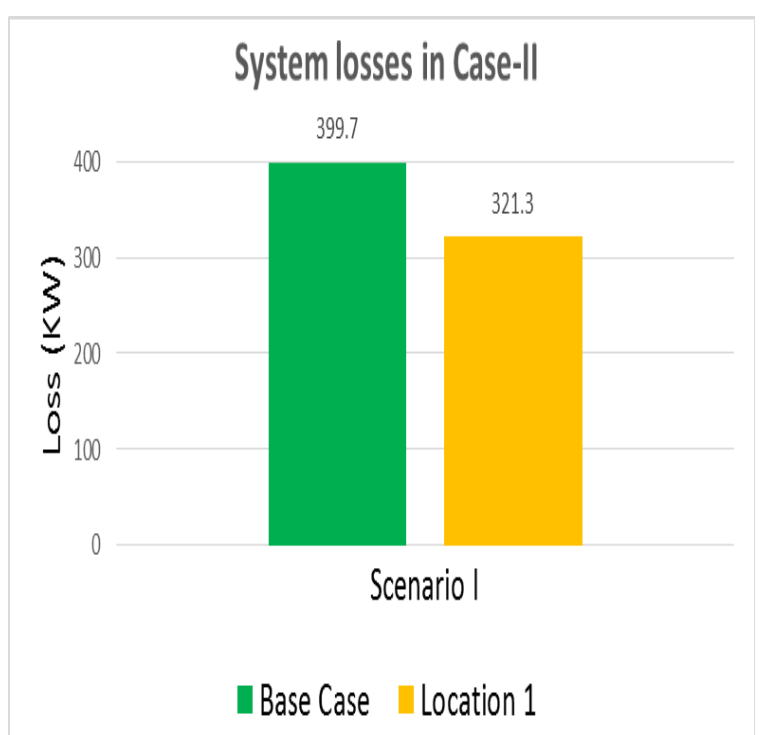

Fig. 12. Power losses of the system in case of active power injected by DG unit.

\section{CONCLUSION AND FUTURE WORK}

Analyzing the assorted impacts of DG units on distributed system is of most significance. Some vital factors such as type, size and location of DG units are important for proper utilization of DG units. The detailed analysis in this research work showed diverse impacts of DG on voltage profile and power losses. It is investigated that connecting synchronous generator as a DG unit near to load centers will improve voltage profile and reduce power losses. While connecting induction generator 


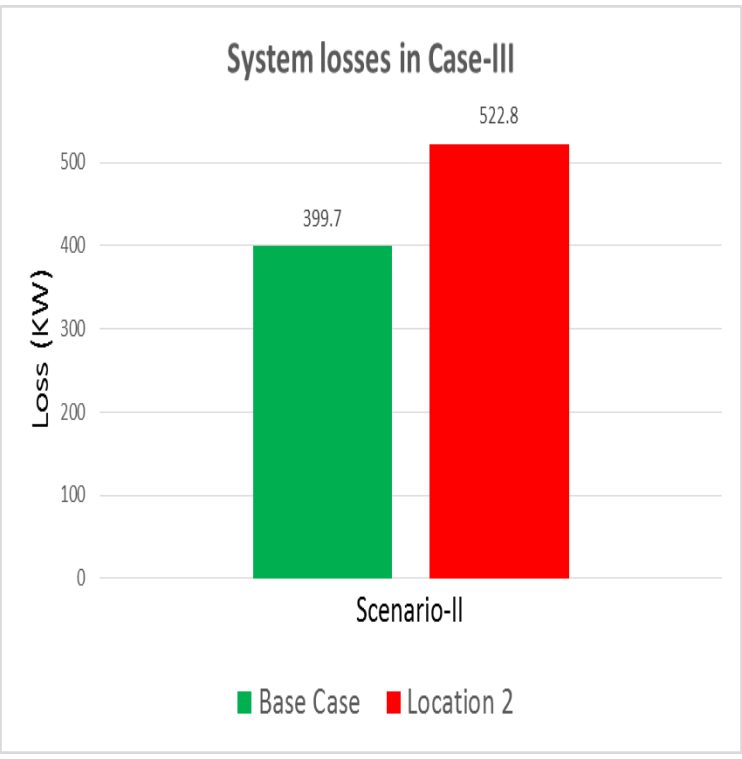

Fig. 13. Power losses of the system in case of injecting induction generator as a DG unit.

as DG unit near to load centers have positive impact on voltage profile but it caused increase in power losses due to absorption of reactive power by induction generator. In future several DG technologies either conventional or non-conventional, can be evaluated for their various impacts on distribution system.

\section{REFERENCES}

[1] H. Iyer, S. Ray, and R. Ramakumar, "Assessment of distributed generation based on voltage profile improvement and line loss reduction," in 2005/2006 IEEE/PES Transmission and Distribution Conference and Exhibition, 2006.
[2] P. Chiradeja and R. Ramakumar, "An approach to quantify the technical benefits of distributed generation," IEEE Transactions on energy conversion, vol. 19, no. 4, pp. 764-773, 2004.

[3] H. B. Puttgen, P. R. Macgregor, and F. C. Lambert, "Distributed generation: Semantic hype or the dawn of a new era?" IEEE power and energy magazine, vol. 99, no. 1, pp. 22-29, 2003.

[4] E. K. Bawan, "Distributed generation impact on power system case study: Losses and voltage profile," in Power Engineering Conference (AUPEC), 2012 22nd Australasian Universities. IEEE, 2012, pp. 1-6.

[5] P. Dondi, D. Bayoumi, C. Haederli, D. Julian, and M. Suter, "Network integration of distributed power generation," Journal of power sources, vol. 106, no. 1, pp. 1-9, 2002.

[6] T. Ackermann, G. Andersson, and L. Söder, "Distributed generation: a definition," Electric power systems research, vol. 57, no. 3, pp. 195-204, 2001.

[7] S. Ahmad, S. Sardar, A. U. Asar, and B. Noor, "Impact of distributed generation on the reliability of local distribution system," INTERNATIONAL JOURNAL OF ADVANCED COMPUTER SCIENCE AND APPLICATIONS, vol. 8, no. 6, pp. 375-382, 2017.

[8] D. Caples, S. Boljevic, and M. F. Conlon, "Impact of distributed generation on voltage profile in $38 \mathrm{kv}$ distribution system," in Energy Market (EEM), 2011 8th International Conference on the European. IEEE, 2011, pp. 532-536.

[9] A. Bayat, A. Bagheri, and R. Noroozian, "Optimal siting and sizing of distributed generation accompanied by reconfiguration of distribution networks for maximum loss reduction by using a new uvda-based heuristic method," International Journal of Electrical Power \& Energy Systems, vol. 77, pp. 360-371, 2016.

[10] P. Mohammadi, H. El-Kishyky, M. Abdel-Akher, and M. Abdel-Salam, "The impacts of distributed generation on fault detection and voltage profile in power distribution networks," in Power Modulator and High Voltage Conference (IPMHVC), 2014 IEEE International. IEEE, 2014, pp. 191-196.

[11] M. A. Aman, S. Ahmad, and K. Mahmood, "Designing and strategic cost estimation of stand-alone hybrid renewable energy system," 2016.

[12] A. Saidian, D. Mirabbasi, and M. Heidari, "The effect of size of dg on voltage flicker and voltage sag in closed-loop distribution system," in Industrial Electronics and Applications (ICIEA), 2010 the 5th IEEE Conference on. IEEE, 2010, pp. 68-72.

[13] Q. Sun, Z. Li, and H. Zhang, "Impact of distributed generation on voltage profile in distribution system," in Computational Sciences and Optimization, 2009. CSO 2009. International Joint Conference on, vol. 1. IEEE, 2009, pp. 249-252. 